\title{
EFFECT OF AQUEOUS EXTRACT OF CITRULLUS LANATUS PULP ON SCOPOLAMINE INDUCED COGNITIVE DYSFUNCTION IN SWISS ALBINO MICE
}

\author{
DIVYA N* \\ Department of Pharmacology, CL Baid Metha College of Pharmacy, Chennai, Tamil Nadu, India. Email: divyarulz.u@gmail.com
}

Received: 13 March 2021, Revised and Accepted: 14 April 2021

ABSTRACT

Objective: Amnesia is a medical condition involving the loss of memory. The memory loss is attributed to a number of illnesses or factors including Alzheimer's disease (AD) and dementia, amnesia is often caused by head injury, brain trauma, or brain surgery. The incidence of amnesia affects only a small percent of the world's population, the relevant study is becoming increasingly important with the rising numbers of people with AD. Alzheimer's is predicted to strike 34 million people globally by 2025 and 14 million within the U.S. alone over subsequent 40 years.

Methods: The study the possible protective effect of aqueous extract of Citrullus lanatus pulp (ACL) using scopolamine-induced amnesia in Swiss Albino mice. Mice of Groups I, II, and III were treated with mice feed and water ad libitum. While, Groups IV, V, and VI received mice feed and ACL 25\%, $50 \%$, and $100 \%$ instead of water, for 21 days. The animals were subjected to a single dose of scopolamine (1 mg/kg b.wt. ip) except in Group I on the 21st day $60 \mathrm{~min}$ after respective drug administration and observed for the effects in brain activity for the learning and memory. The passive avoidance, Morris water maze, Y-Maze, and elevated plus maze were used as a tool for cognitive dysfunction study.

Results: The ACL significantly reversed the scopolamine induced amnesia in mice. This is evident as $C$. lanatus is rich in lycopene content. The experimental models demonstrated that all the concentration of ACL treated mice showed remarkable results in restoring the effect of amnesia induced by scopolamine.

Conclusion: To concise, these results suggest that ACL may exhibit protective effect on the brain to reverse the scopolamine induced amnesia. Further, it can be explored extracting the lycopene content of watermelon.

Keywords: Citrullus lanatus, Watermelon, Amnesia, Cognitive dysfunction, Scopolamine.

(C) 2021 The Authors. Published by Innovare Academic Sciences Pvt Ltd. This is an open access article under the CC BY license (http://creativecommons.org/ licenses/by/4.0/) DOI: http://dx.doi.org/10.22159/ajpcr.2021v14i5.30066. Journal homepage: https://innovareacademics.in/journals/index.php/ajpcr

\section{INTRODUCTION}

A decline in cognitive abilities results in a neurodegenerative disorder called amnesia which may be one of the symptoms of some neurodegenerative diseases such as Alzheimer's disease (AD) [1,2]. As per the WHO guidelines, Amnesia, the main feature is the loss of memory, usually of important recent events, that is undue to organic mental disorder and is too great to be explained by common forgetfulness or fatigue. Amnesia is typically centered on traumatic events, such as accidents or unexpected bereavements, and is normally partial and selective Complete and generalized amnesia is uncommon and is ordinarily part of a fugue. If this is the case, the disorder should be categorized as such. The diagnosis should not be made in the presence of organic brain disorders, intoxication, or excessive fatigue. Scopolamine is a muscarinic receptor antagonist with profound amnesic effects in a range of learning paradigms and a helpful experimental pharmacological model to study the pathophysiology of the cognitive deficiency in $\mathrm{AD}$ [3]. It has been extensively implicated to cause amnesia and a viable model of dementia in humans and animals [4]. The cholinergic function is restored through prolongation of the availability of acetylcholine (Ach) released into the neuronal synaptic cleft by inhibiting acetylcholinesterase (AChE) activity, remains a rational target in the treatment of AD. AChE inhibitors (piracetam, tacrine, donepezil, and rivastigmine) are the mainstay in the treatment of $\mathrm{AD}$, though effective not without adverse effects $[5,6]$.

According to the WHO, more than $80 \%$ of the world's population relies on traditional herbal medicine for their primary healthcare. India is rich in biodiversity and knowledge-rich ancient traditional system of medicine namely Ayurveda, Siddha, Unani, and local health ideas contributes a strong base for the utilization of a large number of plants in general healthcare of the people [7].

Citrullus lanatus citroides, commonly known as a watermelon, belonging to the family Cucurbitaceae is native to India. It is found in forest lands, riversides, and wasteland, and gets cultivated on a large scale. It is an excellent source of arginine, Vitamins A, B, and C, carotenoids, lycopene, carbohydrates, sodium, magnesium, potassium, and water [8]. C. lanatus sp. is a natural source of antioxidants such as beta carotene, Vitamin C, and citrulline.

Its red mesocarp is an excellent source of lycopene. There are evidences to support the tissue protective effects of watermelon juice. Further, the protective effects of watermelon as antimicrobial [9], antigiardial [10], hepatoprotective [11], antiulcerogenic [12], anti-diabetic [13], laxative [14], antiprostatic, Hyperplasia [15], antioxidant [16], analgesic [17], and antiinflammatory [18] effects of watermelon were documented. Mice pre- treated with watermelon juice boosted antioxidant status and offered some protection against acute alcohol induced oxidative injury in brain and liver [19]. It is also a brain tonic [20].

This study was undertaken to evaluate the potential benefits of $C$. lanatus pulp using mice as an animal model for the treatment of Amnesia.

\section{MATERIALS AND METHODS}

Collection, authentication, and preparation of juice Watermelon fruits (green skin and red flesh) were procured identified and authenticated by Prof P. Jayaraman, Ph.D Reg. No PARC/2017/3433. 
A voucher specimen was submitted at C.L. Baid Metha College of Pharmacy, Chennai-97.

The ripe mesocarp of watermelon fruit was chopped into thin slices, using a blender crushed to juice and filtered through a fine mesh muslin cloth to get the fresh watermelon fruit juice, that is, $100 \%$ concentration. A $25 \%$ and $50 \%$ concentration were prepared by diluting a pure watermelon juice with filtered tap water in the ratio of (1: 3 and $1: 1)(\mathrm{v} / \mathrm{v})[8,21,22]$

\section{Animals and experimental design}

A total of 30 Swiss Albino Mice (25-30 g) were procured acclimatized and maintained at $25 \pm 2^{\circ} \mathrm{C}$ and kept in well ventilated animal house under with free access to food and water ad libitum. The experimental protocol presented in the present study was approved by Institutional Animal Ethical Committee of C.L. Baid Metha College of Pharmacy. (Reg No:321/P0/Re/S/01/CPCSEA)

Mice were divided into six groups of five animals in each group.

Group I - Normal Water ad libitum.

Group II - Normal water ad libitum + On the 21 days Scopolamine was injected (1 mg/kg,i.p.).

Group III- Normal water ad libitum + Piracetam (200mg/kg,i.p.) injected for 20 days + On the 21 days Scopolamine was injected (1mg/kg,i.p.).

Groups IV, V, and VI- 25\%, 50\%, and 100\% ACL, respectively, ad libitum for 20 days + On the 21 days Scopolamine was injected (1 mg/kg,i.p.).

\section{Models employed for evaluation of memory enhancing activity in mice}

\section{Passive-avoidance test (PA) [23]}

The apparatus has a box with three walls of wood measuring $27 \mathrm{~cm}$ each and a wall of Plexiglass, a grid floor with $3 \mathrm{~mm}$ stainless steel rods set $8 \mathrm{~mm}$ apart with a wooden platform within the center of the grid floor measuring $(10 \mathrm{~cm} \times 7 \mathrm{~cm} \times 1.7 \mathrm{~cm})$. $20 \mathrm{~V}$, A/C Electric shock was delivered to the grid floor. During the training session, each mouse was gently put on the wooden platform which was set in the center of the grid floor, when the mouse stepped down and placed all its paw on the grid floor and shocks were delivered for $15 \mathrm{~s}$ and therefore the step down latency (SDL) was recorded. The time taken by the mouse to step down from the wooden platform to grid floor with its entire paw on the grid floor was defined as the SDL. Animals that showed SDL in the range of 2-15 s during the first session were used for the second session and in the retention test. The second session was carried out after 90 min from the first test. During the second session, if the animals stepped down before the $60 \mathrm{~s}$, electric shocks were delivered once more for $15 \mathrm{~s}$. During the second test, those animals were removed from the shock-free zone if they did not step down for a period of $60 \mathrm{~s}$ and subjected to a retention test. On the 20 days, after the treatment of last dose training was given and memory retention was examined after $24 \mathrm{~h}$ (i.e., on 21 days) in a similar manner, except that the electric shocks were withdrawn from the grid floor observing an upper cut off time of $300 \mathrm{~s}$.
Elevated plus maze (EPM) [24-26]

The elevated plus-maze for mice has two open arms $(16 \mathrm{~cm} \times 5 \mathrm{~cm})$ and two covered arms $(16 \mathrm{~cm} \times 5 \mathrm{~cm} \times 15 \mathrm{~cm})$ extended from a central platform $(5 \mathrm{~cm} \times 5 \mathrm{~cm})$ from the floor the maze was elevated to a height of $25 \mathrm{~cm}$. On day 1, each mouse was placed at the end of an open arm, far away from the central platform. The time taken by the animal to move from the open arm into one of the closed arms with all its four legs was defined as Transfer latency (TL). TL was recorded on the $1^{\text {st }}$ day (i.e., 20 days of drug administration) for each animal. The animal that did not enter any one of the covered arms within 90 s, was gently pushed into one of the two closed arms, TL was designated as $90 \mathrm{~s}$. Allowed the mouse to examine the maze for another 2 min and then returned to its home cage. Retention of this learned task memory was tested after $24 \mathrm{~h}$ (21 day).

\section{Morris water maze (MWM) [27]}

Spatial learning and memory were estimated by the MWM. The method was to perform a place navigation test from days 1 to 4 , in which the escape latency (EL), the time required to escape onto the hidden platform were used to access learning and memory function. Mice were returned to a home cage once they found the platform and remained on the platform for the $20 \mathrm{~s}$. If mice did not reach the platform within $120 \mathrm{~s}$, it was gently supervised to the platform by the experimenter, where it remained for $20 \mathrm{~s}$. The last trial was recorded as the probe test on day 5 after removal of the platform which was conducted to test the ability of mice to find the removed platform by memory.

\section{Y maze Test (YM) [4]}

The behavioral test was conducted in a large quiet room. A stopwatch was used to score the behaviors and all events were observed manually. A YM is made up of three uniformly spaced arms, labeled as A, B, and C which is $120^{\circ}$ from each other, $41 \mathrm{~cm}$ long, and $15 \mathrm{~cm}$ high and was used to evaluate the spontaneous alternation in the mice. The floor of the apparatus is $5 \mathrm{~cm}$ wide and is equalized with saw shaves. Each mouse was allowed to spontaneously explore the maze by placing in one of the arms. The series of consecutive entrances of the animals into the arms is termed an alternation. The total number of arms entered minus two is termed spontaneous alternations, and the percentage alternation was calculated as ([actual alternations/maximum alternations] $\times 100$ ). 5 min was allotted as the test time limit for each of the animals in the YM apparatus. Recorded data are the total arm entries that indicate the total number of a single-arm entered (e.g., ABCBCABACBC, contain 11 entries), from which the correct and incorrect alternations were recorded.

\section{Statistical Analysis}

Data were analyzed using one-way ANOVA and expressed as mean \pm standard deviation. Statistical studies were performed using GraphPad Prism version 7.04, for windows (GraphPad Software, San Diego, CA). Differences between mean values of different groups were analyzed statistically significant at $*-p<0.05$,

${ }^{* *}-\mathrm{p}<0.01,{ }^{* * *}-\mathrm{p}<0.0001$, ns-Non-significant

\section{RESULTS}

Effect of ACL on scopolamine induced alteration in behavior parameter

\begin{tabular}{|c|c|c|c|c|}
\hline Groups & PA L (sec) & EPM TL (sec) & MWM EL (sec) & Y M \% alterations \\
\hline Group I & $43.83 \pm 1.24$ & $31.21 \pm 1.04$ & $10.22 \pm 0.96$ & $47.85 \pm 1.45$ \\
\hline Group II & $26.50 \pm 0.53 \mathrm{a}^{* * *}$ & $65.53 \pm 1.12 \mathrm{a}^{* * *}$ & $6.08 \pm 1.20 \mathrm{a}^{* *}$ & $31.97 \pm 2.54 \mathrm{a}^{* * *}$ \\
\hline Group III & $39.50 \pm 0.74 a^{\text {ns }} b^{* * *}$ & $18.01 \pm 1.56 \mathrm{a}^{* * *} \mathrm{~b}^{* * *}$ & $16.12 \pm 0.44 \mathrm{a}^{* * *} \mathrm{~b}^{* * *}$ & $42.95 \pm 1.32 \mathrm{a}^{\mathrm{ns}} \mathrm{b}^{* *}$ \\
\hline Group IV & $32.03 \pm 1.31 a^{* * *} b^{\mathrm{ns}} \mathrm{c}^{* *}$ & $38.53 \pm 0.60 a^{* *} b^{* * *} c^{* * *}$ & $12.65 \pm 0.57 a^{\text {ns }} b^{* * *} c^{*}$ & $32.73 \pm 1.11 \mathrm{a}^{* * *} \mathrm{~b}^{\mathrm{ns}} \mathrm{c}^{* *}$ \\
\hline Group V & $35.33 \pm 1.53 a^{* *} b^{* * *} c^{\text {ns }}$ & $25.94 \pm 1.74 a^{\text {ns }} b^{* * *} c^{* *}$ & $14.09 \pm 0.25 \mathrm{a}^{*} \mathrm{~b}^{* * *} \mathrm{c}^{\mathrm{ns}}$ & $35.13 \pm 1.36 a^{* * *} b^{n s} c^{*}$ \\
\hline Group VI & $38.59 \pm 1.85 a^{\text {ns }} b^{* * *} c^{n s}$ & $40.43 \pm 1.29 a^{* * *} b^{* * *} c^{* * *}$ & $15.74 \pm 0.54 \mathrm{a}^{* * *} \mathrm{~b}^{* * *} \mathrm{c}^{\mathrm{ns}}$ & $39.56 \pm 1.78 \mathrm{a}^{*} \mathrm{~b}^{*} \mathrm{c}^{\mathrm{ns}}$ \\
\hline
\end{tabular}

All the values are expressed as mean \pm SEM. ${ }^{* * *}-\mathrm{p}<0.001,{ }^{* *}-\mathrm{p}<0.01,{ }^{*}-\mathrm{p}<0.05$, ns-non-significant; Group I versus Groups II, III, IV, V, and VI considered as a. Group II versus Groups III, IV, V, and VI considered as b; Group III versus Groups IV, V, and VI considered as c (one-way ANOVA followed by Tukey test). ANOVA - Analysis of variance; SEM - Standard error of the mean; ACL - Aqueous extract of Citrullus lanatus; \% alterations -- \% of spontaneous alteration in the arms; EL: Escape latency; TL: Transfer latency; L: Latency 


\section{Effect of ACL on PA test}

There was a significant difference between groups in the retention test.

When compared to Group I, Groups II and IV significant $(\mathrm{p}<0.001)$, Group V $(\mathrm{p}<0.01)$ Groups III and VI non-significant and decreased in the retention test.

When compared to Group II, Groups III, V, and VI significant $(\mathrm{p}<0.001)$, Group IV non-significant and increased latency during retention test.

When compared to Group III, Group IV significant ( $\mathrm{p}<0.01$ ) Groups V and VI non-significant and decreased latency in retention test. Results are shown in Fig. 1.

\section{Effect of ACL on EPM test}

TL on retention of information or memory.

When compared to Group I, Groups II and VI significantly increased $(\mathrm{p}<0.001)$ Groups III $(\mathrm{p}<0.001)$ and V non significantly decreased, Group IV $(\mathrm{p}<0.01)$ significantly increased TL.

When compared to Group II, Groups III, IV, V, and VI significantly decreased TL $(\mathrm{p}<0.001)$.

When compared to Group III, Groups IV and VI $(\mathrm{p}<0.001)$ Group V $(p<0.01)$ significantly increased TL. Results are shown in Fig. 2.

\section{Effect of ACL on MWM test}

In the probe trial followed by last training session, EL was calculated.

When compared to Group I, Group II significantly decreased ( $\mathrm{p}<0.001)$ and Groups III, IV, V, and VI non significantly increased EL.

When compared to Group II, Groups III, IV, V, and VI significantly increased EL $(\mathrm{p}<0.001)$.

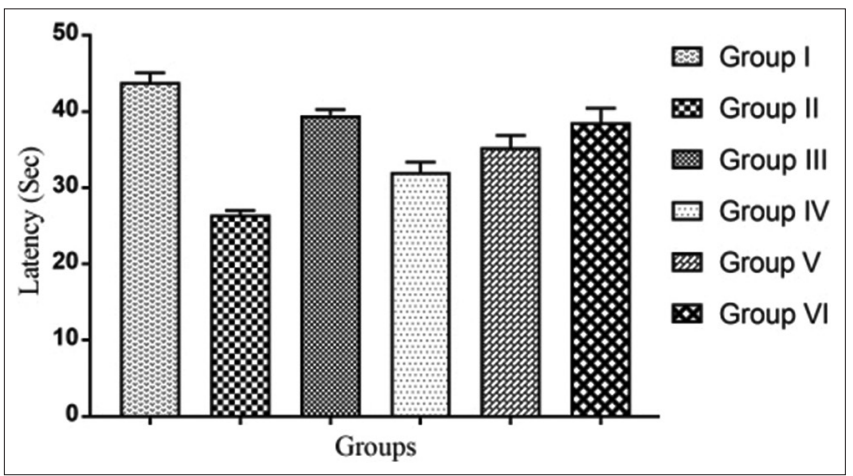

Fig. 1: Effect of ACL on PA test

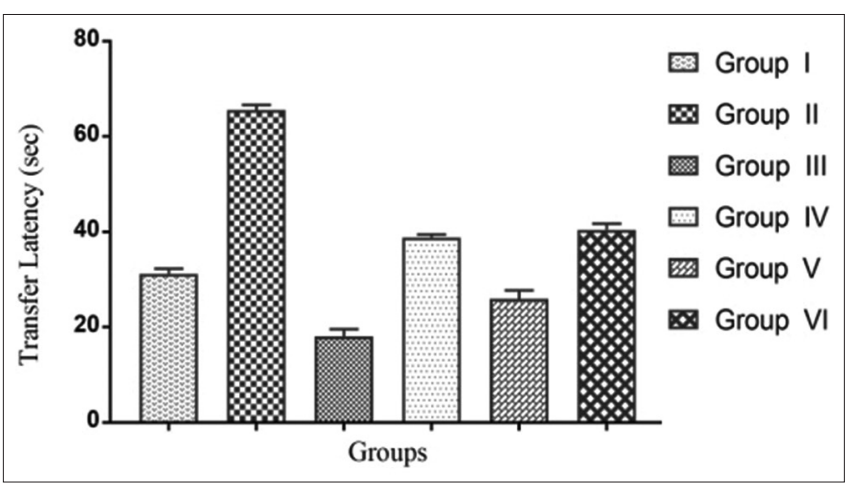

Fig. 2: Effect of ACL on EPM test
When compared to Group III, Groups IV, V, and VI non significantly decreased EL. Results are shown in Fig. 3.

\section{Effect of ACL on YM test}

In the probe trial followed by last training session,

When compared to Group I, Groups II, IV, and V significant $(\mathrm{p}<0.001)$, Group III non-significant, Group VI $(\mathrm{p}<0.05)$ and decreased Spontaneous alternation.

When compared to Group II, Group III significant $(\mathrm{p}<0.01)$ Groups IV, V. and VI non-significant and increased Spontaneous alternation.

When compared to Group III, Group IV significant ( $\mathrm{p}<0.01)$, Groups V and VI non-significant and decreased Spontaneous alternation. Results are shown in Fig. 4

\section{DISCUSSION}

$\mathrm{AD}$ is a neurodegenerative disorder correlated with a deterioration in cognitive skills [28], which mostly affects the elderly population. The AD pathophysiology is complex including defective beta-amyloid protein metabolism, abnormalities of glutaminergic, adrenergic, serotonergic, and dopaminergic neurotransmission, and the potential involvement of inflammatory and oxidative pathways [29]. Hence, the present study focuses on the exploration of the memory-enhancing activity of the aqueous extract of $C$. lanatus in a scopolamine-induced amnesia mice model.

Watermelon juice is a valuable source of phenolics, $\alpha$ tocopherol, and carotenoids such as beta-carotene and lycopene, and Vitamin C [30,31]. The antioxidant properties are accountable for the beneficial effects of Vitamin C [32]. Watermelon juice is an excellent source of lycopene, having about $40 \%$ higher lycopene content than raw tomatoes [33,34]. Studies have attributed the antioxidant properties of watermelon juice to its high lycopene content $[35,36]$. There is compelling evidence for

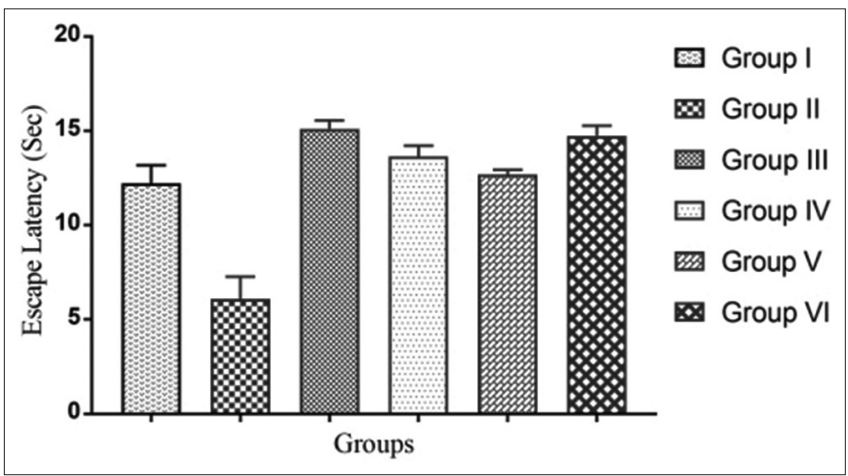

Fig. 3: Effect of ACL on MWM test

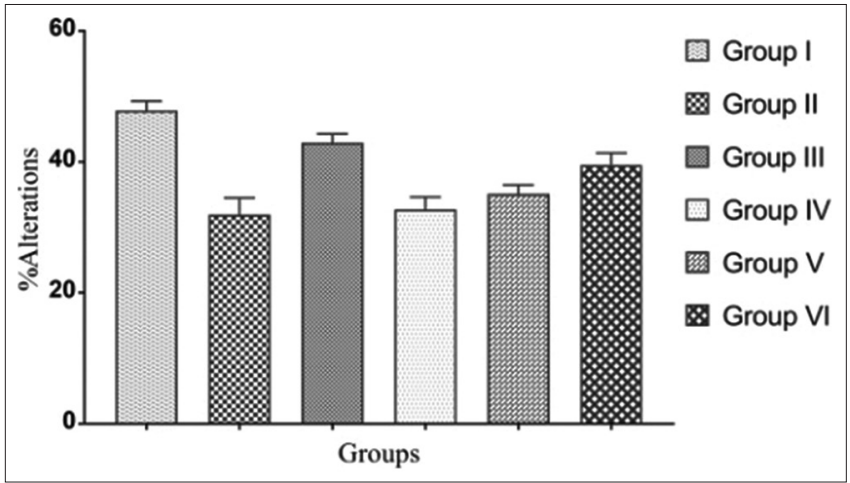

Fig. 4: Effect of ACL on YM test 
the antioxidant role of lycopene in animal models of toxicant-induced toxicities. Lycopene induces enzymes of the cellular antioxidant defense systems by stimulating the antioxidant response element transcription system [37].

The first representation of the Nootropic class of agents is Piracetam, which proves to improve memory deficiencies in individuals. Repeated injection of piracetam had improved the learning abilities and memory capacities of laboratory animals [38]. Scopolamine is an antimuscarinic agent, competitively antagonizes the effect of Ach on the muscarinic receptors by occupying postsynaptic receptor sites with high affinity and increases AChE activity in the cortex and hippocampus. Scopolamine decreases cerebral blood flow due to cholinergic hypofunction. Scopolamine also triggers reactive oxygen species, inducing free-radical injury and there is an elevated myelodysplastic syndromes level in scopolamine-treated group brain, and deterioration in antioxidant levels. Scopolamine induces neuroinflammation by promoting a high level of oxidative stress and pro-inflammatory cytokines in the hippocampus, and increased levels of APP and Tau is due to scopolamine. Significant histopathological changes in the cerebral cortex, including neuronal degeneration, were noticed on the administration of scopolamine [39].

The present study evaluates, Scopolamine-induced cognitive dysfunction that is extensively used to probe potential therapeutic agents attenuating cognitive deficits and the effect of ACL $25 \%, 50 \%$, and $100 \%$ in scopolamine-induced amnesia in mice. The MWM, EPM, $\mathrm{PA}$, and YM were performed to screen the effect of drugs.

PA, a fear-aggravated experiment used to evaluate learning and memory in rodent models of CNS disorder [40]. The method was developed to study the learning and memory in mice by evaluating PA and escapelearning responses simultaneously. Prolongation of the step-down latency and shortening of the EL in the retention test depends on the power of the voltage of the electric shocks given during the training test. The step-down latency and EL may be good parameters of learning and memory performance and is significant [41]. ACL increased SDL induced by i.p. treatment of scopolamine in the retention trial. This implies that the animal has the retention of memory of the shock once entered in the shock-free zone.

An elevated plus-maze consisting of two open and two enclosed arms was used for an evaluation of memory in mice. Mice in the plus-maze escaped from the open arm to the enclosed arm as mice dislike open and high spaces. The time it took for the mice to move from the open arm to the enclosed arm (TL) was recorded and the results suggested that TL may be one of the parameters of learning and memory [25]. In the elevated plus-maze, a decrease in TL during probe trial indicated the development of memory.

MWM was employed as behavioral models for evaluation of learning and memory [27] MWM is generally accepted as an indicator of spatial learning and reference memory. It is a reliable and convenient method to assess hippocampal-dependent cognitive function in rodents [42]. ACL reversed scopolamine-induced memory impairment in the MWM test by increasing the EL in the probe test. These results suggest that ACL attenuates long-term and reference memory impairment induced by scopolamine through the rescue by antioxidant mechanisms and Ach system.

Using a YM test, spontaneous alternation was calculated to show habituation and spatial working memory [43]. Evaluation of exploratory behavior in mice is studied using Spontaneous Alternation Tests. Brain areas involved in this test include the hippocampus, septum, basal forebrain, and prefrontal cortex. ACL treated mice showed an increase in spontaneous alterations than the scopolamine injected mice.

The protective effect of $C$. lanatus may be due to lycopene content. Lycopene has been proved as a neuroprotective agent against scopolamine-induced neurotoxicity in rats and it was suggested as an encouraging candidate for AD treatment and established evidence for the potential of lycopene in the management of scopolamine induced amnesia [44]

\section{CONCLUSION}

The results of our study prove that watermelon shows neuroprotective and improved cognitive could be due to the synergistic effect of the phytoconstituents, further can be explored on the phytoconstituent present for valued treatment of $\mathrm{AD}$

\section{AUTHORS CONTRIBUTION}

Ms. Divya N has done the collection, extraction, and experiments of C. lanatus pulp using Swiss Albino mice.

\section{CONFLICTS OF INTEREST}

No conflicts of interest.

\section{AUTHORS FUNDING}

No external funding was received for the research/publication of this article,

\section{REFERENCES}

1. Bowen DM, Smith CB, White P, Dawson AN. Neurotransmitterrelated enzymes and indices of hypoxia in senile dementia and other abiotrophies. Brain 1976;99:459-96.

2. Whitehouse PJ, Price DL, Clark AW, Coyle JT, DeLong MR. Alzheimer disease: Evidence for selective loss of cholinergic neurons in the nucleus basalis. Ann Neurol 1982;10:122-6.

3. Klinkenberg I, Blokland A. The validity of scopolamine as a pharmacological model for cognitive impairment: A review of animal behavioral studies. Neurosci Biobehav Rev 2010;34:50.

4. Imam A, Ajao MS, Ajibola MI, Amin A, Abdulmajeed WI, Lawal AZ, et al. Black seed oil ameliomiceed scopolamine-induced memory dysfunction and cortico-hippocampal neural alterations in male Wistar mices. Bull Fac Pharm Cairo Univ 2016;54:49-57.

5. Bores GM, Huger FP, Petko W, Mutlib AE, Camacho F, Rush DK, et al. Pharmacological evaluation of novel Alzheimer's disease therapeutics: Acetylcholinesterase inhibitors related to galantamine. J Pharmacol Exp Ther 1996;277:728-38.

6. Allain H, Bentue-Ferrer D, Tribut O, Gauthier S, Michel BF, Drieu-La RC. Alzheimer's disease: The pharmacological pathway. Fundam Clin Pharmacol 2003;17:419-28

7. Vaghela B, Buddhadev S, Shukla L. Pharmacological activities of Desmodium gangeticum: An overview. An Int J Pharm Sci 2013;4:264-78.

8. Yativ M, Harary I, Wolf S. Sucrose accumulation in watermelon fruits: Genetic variation and biochemical analysis. J Plant Physiol 2010;167:589-96.

9. Adunola AT, Chidimma AL, Olatunde DS, Peter OA. Antibacterial activity of watermelon (Citrullus lanatus) seed against selected microorganisms. Afr J Biotechnol 2015;14:1224-9.

10. Hassan LE. In vitro antigiardial activity of Citrullus lanatus var. citroides extracts and cucurbitaceous isolated compounds. J Med Plants Res 2011;5:3338-46.

11. Madhavi P, Vakati K, Rahman H. Hepatoprotective activity of Citrullus lanatus seed oil on ccl4 induced liver damage in rats. SAJP 2012;1:30-3.

12. Bhardwaj A, Kumar R, Dabas V, Alam N. Evaluation of anti-ulcer activity of Citrullus lanatus seed extract in wistar albino rats. Int $\mathrm{J}$ Pharm Pharm Sci 2012;4:135-9.

13. Jiyun A, Wonhee C, Suna K, Taeyoul H. Anti-diabetic effect of watermelon (Citrullus vulgaris Schrad) on Streptozotocin-induced diabetic mice. Food Sci Biotechnol 2011;20:251-4.

14. Sharma S. First report on laxative activity of Citrullus lanatus. Pharmacol Online 2011;2:790-7.

15. Olamide AA, Olayemi OO, Demetrius OO, Olatoye OJ, Kehinde AA. Effects of methanolic extract of Citrullus lanatus seed on experimentally induced prostatic hyperplasia. Eur J Med Plants 2011;1:171-9.

16. Gill NS. Evaluation of antioxidant activity of Citrullus lanatus seed extract in rats. Lat Am J Pharm 2011;30:429.

17. Kumari A, Rao J, Kumari J. Analgesic activity of aqueous extract of Citrullus lanatus peels. Advin Pharmacol Pharma 2013;1:135-8 
18. Abdelwahab I, Hassan LE, Hasnah MS, Yagi SM, Koko WS, Mohan S, et al. Anti-inflammatory activities of Cucurbitacin E isolated from Citrullus lanatus var. citrodies: Role of reactive nitrogen species and cyclooxygenase enzyme inhibition. Fitoterapia 2011;82:1190-7.

19. Oyenihi OR, Afolabi BA, Oyenihi AB, Ogunmokun OJ, Oguntibeju $\mathrm{OO}$. Hepato-and neuro-protective effects of watermelon juice on acute ethanol-induced oxidative stress in mices. Toxicol Rep 2016;3:288-94.

20. Mabberley DI. The Plant Book. Cambridge, New York: Cambridge Cambridge University Press; 1987.

21. Oluwole FS, Balogun ME. Antisecretory effects of watermelon (Citrullus lanatus) juice in male albino mices. Ann Revi Res Biol 2013;3:358-66.

22. Mohammad MK, Mohamed MI, Zakaria AM, Razak HR, Saad WM. Watermelon (Citrullus lanatus (Thunb.) Matsum. and Nakai) juice modulates oxidative damage induced by low dose x-ray in mice. Biomed Res Int 2014;2014:512834.

23. Ohno M, Sametsky EA, Younkin LH, Oakley H, Younkin SG, Citron M, et al. BACE1 deficiency rescues memory deficits and cholinergic dysfunction in a mouse model of Alzheimer's disease. Neuron 2004;41:27-33.

24. Dhingra D, Parle M, Kulkarni SK. Memory enhancing activity of Glycyrrhiza glabra in mice. J Ethnopharmacol 2004;91:361-5.

25. Itoh J, Nabeshima T, Kameyama T. Utility of an elevated plus-maze for the evaluation of memory in mice: Effects of nootropics, scopolamine and electroconvulsive shock. Psychopharmacology 1990;101:27-33.

26. Parle M, Dhingra D. Ascorbic acid: A promising memory-enhancer in mice. J Pharmacol Sci 2003;93:129-35.

27. Morris R. Developments of a water-maze procedure for studying spatial learning in the rat. J Neurosci Methods 1984;11:47-60.

28. Cummings JL, Cole G. Alzheimer's disease. JAMA 2002;287:2335-48.

29. Kang SY, Lee KY, Koo KA, Yoon JS, Lima SW, Kima YC, et al. ESP-102, a standardized combined extract of Angelica gigas, Saururus chinensis and Schizandra chinensis, significantly improved scopolamine-induced memory impairment in mice. Life Sci 2005;76:1691-705.

30. Charoensiri R, Kongkachuichai R, Suknicom S, Sungpuag P. Betacarotene, lycopene, and alpha-tocopherol contents of selected Thai fruits. Food Chem 2009;113:202-7.

31. Chaturvedi P, Pipedi-Tshekiso M, Tumed A. Supplementation with watermelon renders protection against toxicity induced by paracetamol in albino rats: The mutual and fine interaction of antioxidants prevented the cellular damage. Int J Food Agric Vet Sci 2014;4:102-11.

32. Balahoroğlu R, Dülger H, Özbek H, Bayram İ, Şekeroğlu MR. Protective effects of antioxidants on the experimental liver and kidney toxicity in mice. Eur J Gen Med 2009;5:157-64

33. Seif HS. Ameliorative effect of pumpkin oil (Cucurbita pepo L.) against alcohol-induced hepatotoxicity and oxidative stress in albino rats. Beni Suef Univ J Basic Appl Sci 2014;3:178-85.

34. Kasdallah-Grissa A, Mornagui B, Aouani E, Hammami M, El May M, Gharbi N, et al. Resveratrol, a red wine polyphenol, attenuates ethanolinduced oxidative stress in rat liver? Life Sci 2007;80:1033-9.

35. Naz A, Butt MS, Pasha I, Nawaz H. Antioxidant indices of watermelon juice and lycopene extract. Pak J Nutr 2013;12:255-60.

36. Zakaria AM, Ghazali N, Mohammad MK, Mohamed MI, Isa MM, Razak HR, et al. Radioprotective effect of watermelon juice against low dose ionizing radiation-induced inflammatory response in mice. World J Med Sci 2014;10:191-7.

37. Lian F, Wang XD. Enzymatic metabolites of lycopene induce Nrf2mediated expression of phase II detoxifying/antioxidant enzymes in human bronchial epithelial cells. Int J Cancer 2008;123:1262-8.

38. Dementia and Cognitive Impairment Diagnosis and Treatment Guideline; 2012

39. Kaur R, Parveen S, Mehan S, Khanna D, Kalra S. Neuroprotective effect of ellagic acid against chronically scopolamine induced Alzheimer's type memory and cognitive dysfunctions: Possible behavioural and biochemical evidences. Int J Preven Med Res 2015;1:45-64.

40. Available from: http://www.sbfnl.stanford.edu/bml passive.html. [Last accessed on 2018 Mar 28].

41. Kameyama T, Nabeshima T, Kozawa T. Step-down-type passive avoidance-and escape-learning method: Suitability for experimental amnesia models. J Pharmacol Methods 1986;16:39-52.

42. Zhang $\mathrm{O}$, Wang $\mathrm{Q}$, Chen $\mathrm{H}$. Involvement of cholinergic dysfunction and oxidative damage in the effects of simulated weightlessness on learning and memory in rats. Biomed Res Int 2018;2018:2547532.

43. Swonger AK, Rech RH. Serotonergic and cholinergic involvement in habituation of activity and spontaneous alternation of rats in a Y maze. J Comp Physiol Psychol 1972;81:509-22.

44. Bala R, Khanna D, Mehan S, Kalra S. Experimental evidence for the potential of lycopene in the management of scopolamine induced amnesia. RSC Adv 2015;5:72881-92. 